\title{
The future challenge of Earth science education research
}

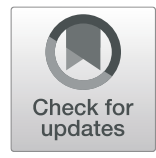

Nir Orion

\begin{abstract}
This article addresses the question of what the future directions and emphases of the research in the earth science education field ought to be. During the past 30 years, Earth science education research has established a solid theoretical foundation, as well as practical strategies and techniques, for a meaningful teaching of earth science from K-12. However, the quality of this research, and the growing need for knowledge in Earth science, have done little to improve the low profile of ESE in schools worldwide. The article posits that narrowing this disturbing gap between the educational potential of Earth science and its low profile in schools requires a holistic agenda. Such an agenda will encompass the deepening of existing research of the Earth systems approach in areas like the development of environmental insight better understanding the learning process as an embedded human instinct, which will hopefully contribute to changing the current essentialism-based teaching culture. However, it will also include new avenues of research focused on changing the attitudes of geoscientists towards their role in society and the adoption of geoethical values.
\end{abstract}

Keywords: Earth science education research, Earth systems education, Instinct of learning, Environmental insight

\section{Introduction}

One of the existential challenges with which citizens in the twenty-first century must contend is coexisting peacefully with the environment. The ability to do this implies having environmental literacy, and the understanding that we are unavoidably participative beings in Earth's systems - that our behavior is constantly affecting and being affected by everything natural and human, in a dynamic relationship (Sterling, 2010). Earth Science is the scientific discipline that explores our planet Earth and provides this knowledge and understanding. It involves almost every critical component of our life on Earth, starting from the air we breathe, the water we drink, the food we eat, the energy we use, the buildings we live and work in, and the materials used for our daily lives. Twenty-First century science tends to adopt an interdisciplinary perspective and a systems approach toward dealing with a broad spectrum of scientific domains. The influence of this tendency is well shown in the geosciences, where the different fields are becoming

Correspondence: nir.orion@weizmann.ac.il Science Teaching Department, Weizmann Institute of Science, 1 Herzl St., 76100 Rehovot, Israel 
great, it would not be an overstatement to conclude that today, at the end of the second decade of the twenty-first century, ESE research has established a solid theoretical foundation for practicing ESE in schools. This foundation encompasses a broad range of aspects that are crucial for effective K-12 Earth Science (ES) teaching. It provides learners with the cognitive skills needed to develop environmental insights - the ability to overcome cognitive barriers to spatial and temporal thinking, retrospection, and understanding phenomena across scales of many orders of magnitude, to integrate diverse subjects, and to develop the cognitive capacity for systems thinking. It includes a solid understanding of the alternative conceptions that students are bringing into the Earth science classroom, and the subjects, methodologies and educational strategies that are most effective for the development of students' thinking skills. Some of these thinking skills, like the understanding of deep time, cyclic thinking and system thinking, are quite unique to ESE, while others, such as logic and scientific thinking, are more general. The research has also suggested how to integrate the indoor learning environments (classroom, lab, computer) with the outdoor learning environments under the umbrella of the holistic Earth systems approach.

And yet, despite the availability of this theoretical and practical research, and the now widespread recognition that understanding Earth's interconnected subsystems is crucial to the future of the world, the status of ESE in schools has remained largely unchanged. Recent surveys (Greco \& Almberg, 2018; King, 2013) have indicated that earth science education in schools worldwide has retained the same low profile that was noted in the previous century (King, Orion, \& Thompson, 1995; Orion, Adams, King, \& Krockover, 1999). Earth science concepts are often wrongly considered of less rigor and substance than other areas of science (Hoffman \& Barstow, 2007), and educational methodologies often neglect the inquiry-based approach and the outdoor learning environment, often leading teachers to merely "teach to the test".

This article addresses the question of what the future directions and emphases of research in the field of earth science education ought to be. Its suggestions for future research efforts are framed as a direct response to the current contrast between the important advances that have been made in the field of Earth science education in the past 30 years, and the relative immobility of its status as a topic of importance in schools. After a brief assessment of this problem's underlying causes, it will provide a summary of the most pressing challenges facing ESE research today, beginning with a series of existing fields of research that should be expanded, and ending with a new proposed avenue of research.

\section{Understanding the problem - why does this gap exist?}

The first stage for those wishing to bridge the gap between the importance and relevance of the Earth science to society and its low status in schools worldwide is to understand why and how it came to be. Orion (2017) suggested that the explanation for this gap is a vicious cycle of unawareness. This cycle includes the improper practice of Earth Science education in most countries. As a result, many students leave school with misconceptions and misapprehensions about the relevance of Earth Science and the importance of Earth Science education. These attitudes perpetuate the narrow perspectives of reductionist policy makers in education, including politicians, scientists, and educators, with the result that there has been no appreciable change in the profile of Earth Science in schools, or in the way that it is taught. This vicious cycle thus continues for generations without any significant progress, a situation that is only amplified by the tendency of geoscientists worldwide to stay away from public activity, including the educational system. Consequently, there is insufficient support for promoting the quality and quantity of earth science in schools.

However, the 'unawareness cycle' is not the ultimate source of the disturbing gap between the potential of Earth science and its low profile in schools. Rather, it is only a symptom of the essentialist philosophy that most schools in most countries preserve and support. Essentialism has been the dominant education approach in public schools worldwide since their foundation in the eighteenth century. This socio-economic approach sees the child as raw material and the school as a means to mold the child into an obedient and productive citizen. Essentialism ignores the element of personal relevance, and students, as individuals, must accept and perform whatever the authorities have decided that they should learn, regardless of how relevant they find it for their present-day life. As a result, many students worldwide find that most of their required subjects are boring, and lose their intrinsic motivation for learning (Imig \& Imig, 2006).

The analysis above suggests that bridging the disturbing gap between the potential of Earth Sciences and its low profile in schools requires the investment of multi directional efforts. Some of these efforts will involve expanding upon preexisting avenues of research, while others will require investing substantially in a new direction designed to bring in a currently underutilized educational asset.

\section{Existing avenues of ESE research that are worth expanding}

The Earth systems education approach has been implemented in several countries over the past two decades. 
This implementation has been followed by studies, which have indicated its ability to raise students' interest and to develop high order thinking skills and environmental literacy (Hoffman \& Barstow, 2007). Moreover, the Earth systems approach was adopted by the International Geoscience Education Organization (IGEO) as the preferred teaching approach for ESE. Nevertheless, the implementation of the Earth systems approach worldwide is still limited, and additional research is therefore needed to study the professional and cultural barriers that hinder this implementation and to generate strategies for overcoming these obstacles. This section names and summarizes several key research objectives in the field of Earth systems education that have yet to be accomplished.

\section{Objective 1: Exploring the development of environmental insight}

There is growing evidence that citizens, young and old, need to be more informed and active in solving global problems, such as the current climate change, the need to exploit new minerals, make sustainable use of water resources and to protect bio- and geodiversity. Citizens cannot understand humankind's rapid impact on Earth's environments without first understanding Earth's processes (Martin, 2018). However, the focus of the traditional environmental movement on the development of environmental awareness has failed to change the environmental behavior of citizens worldwide (Orion \& Libarkin, 2014).

In light of the limitations of the traditional (environmental awareness) approach, researchers have suggested shifting the focus of the environmental movement towards developing environmental insight (Orion, 2007, 2017; Orion \& Fortner, 2003). Environmental insight is composed of two central components: (1) the understanding that we live in a cycling world that is built upon a series of subsystems (geosphere, hydrosphere, biosphere, and atmosphere) that interact through an exchange of energy and materials; and (2) the understanding that people are a part of nature, and thus must act in harmony with its 'laws' of cycling. The study of the interacting Earth systems - within the dimension of deep time and the large spatial scale of geological processes - will enable students to appreciate the realistic influence of humans on the Earth in deep time perception. In addition, it will move away from the traditional altruistic environmental awareness approach towards the environmental insight (egocentric and geocentric) approach.

According to this new educational approach, the ultimate aim of Earth systems education is the development of environmental insight. Orion (2016) noted the relationships between systems thinking skills and the development of environmental insight among high school students and adults. However, an extensive research effort is still needed to explore the influence of system thinking skills and geological deep time perception on the development of environmental insight. Moreover, an additional avenue of study in this area is needed for better, broader and deeper understanding of the meaning of being an environmentally insightful citizen.

\section{Objective \#2: Understanding the relationship between ESE and social wellbeing}

Inquiry-based learning in small groups at school is embedded within the Earth Systems Education (ESE) approach, both in indoor learning environments and in the outdoor learning environment. Thus, the ESE approach creates numerous opportunities for social interaction and depends on students' social ability to interact with their peers in a learning process, and on the ability of teachers to deal with this social aspect. For example, teachers must be able to adjust the space of the laboratory to enable students' mobility between different groups, to facilitate students' interactions and to encourage spontaneous social interactions. Eyov (2017) presented a mechanism of interactions, where a positive social situation that includes social connections or a sense of belonging that stems from the existence of these relationships constitutes a fundamental factor for the development of independent learning skills. Levy, Kaplan, and Assor (2004) reckon that students who are preoccupied with their social function or state in class will find it difficult to focus on learning, due to a conflict between the social need and the educational need. There are several fundamental needs that are essential for the academic success of students in school, including a sense of belonging, a sense of connectedness and security. This social aspect is part of a broad domain called "social wellbeing" (SW). This social-emotional field refers to the subjective assessment of the individual's social functioning and constitutes one of the components in defining the level of an individual's mental health (Keyes, 1998, 2002; Robitschek \& Keyes, 2009). Since learning in school takes place in a social environment, SW is expected to be a main factor that affects the optimal emotional state for learning.

The social aspect is not new in educational research, or in the more specific field of science teaching. In the 1970s-80s many studies were conducted that focused on cooperative learning in the laboratory (Abraham, 1976; Foster \& Penick, 1985; Humphreys, Johnson, \& Johnson, 1982; Johnson, 1976; Okebukola \& Ogunniyi, 1984). However, research in the field of cooperative learning focused on the contribution of co-operation to learning itself, without focusing on the relationship between the social situation of the individual and the emotional state required for the existence of a learning process. It is also important to note that Vygotsky's socio-cultural theory 
deals with students' socio-cultural environment and their cognitive development (Vygotsky, 1962), but does not refer to the emotional-social aspect, and certainly not to social wellbeing.

Under this theoretical framework, it seems relevant to examine the interrelationship between the social wellbeing of Earth science students and the learning and teaching of the ESE approach. This means, on the one hand, assessing the effect of the teaching method on the level of students' SW (Social Wellbeing), and on the other, examining the contribution of SW to the students' engagement in the learning process. This research area might deal with research questions like:

a) What indicators of social wellbeing can be identified among ES students?

b) To what extent does the students' SW affect the level of their engagement in the learning process?

c) What is the effect of the learning method in the ES program on the students' SW?

d) What is the effect of the teaching method on the SW of students?

\section{Objective \#3: Understanding and tapping into the 'learning instinct'}

Earth systems approach is the opposite of the traditional approach to teaching adopted in schools and universities. This traditional way is mainly focused on the transmission of information from teachers to students, who must memorize it and give it back through a onetime event called an 'examination'. In contrast, the Earth systems approach is based on the construction of knowledge by learners through the mediation of the teacher, and is therefore based on a close engagement of the learner in the learning process.

Thus, the shift from traditional teaching to earth systems education requires, among other things, the understanding that learning is a natural process - it is an instinct. The learning mechanism in human beings, as in other animals, is instinctive, and therefore occurs in response to stimulation. Possibly, the difference between humans and other species lies in the relationship between learning and the characteristics of natural and intrinsic motivation for learning. For the human species, learning has evolved far beyond the most basic existential survival, and also serves humans' natural curiosity and the inborn human tendency to seek novelty and challenges. Thus, in humans, the main stimulus for learning is emotional, and the cognitive ability follows this emotional need. Unfortunately, the classic classroom stifles this natural instinct, consequently encouraging boredom, absenteeism, and rebellion among the students.
This gap between the natural instinct of learning and the traditional schooling approach is a central reason for the worldwide phenomenon of children's reluctance to attend and struggle to learn in schools. Children must find their own meaning and relevance in what they learn in school, since this sense of relevance is likely to stimulate their interest in the subject matter, this tapping into their learning instinct. Earth science education has great potential to stimulate students' learning instinct by helping them see the relevance of what they learn in their own daily life. This statement is based on the Earth systems content and the existing ESE research, which highlights the central role of the outdoor learning environment in creating personal relevance. This personal relevance should stimulate the learning instinct mechanism and, once this instinct is active, students will cooperate and engage in the inquiry-based learning. Consequently, with the right program, students can develop high-order thinking skills, such as the ability to discern between an observation, a conclusion and an assumption, to think in a geological time dimension (deep time), and to engage in spatial thinking, threedimensional thinking and system thinking.

Thus, a central component of the ESE research agenda should be the exploration of the interrelationships between the Earth systems education approach and stimulating the learning instincts of earth science learners. This research component should include two aspects. The first aspect should focus on how to identify learners or episodes of learning that are controlled by the learning instincts, and then to study the emotional factors that stimulate the learning instincts of various individuals. The second branch of study should focus on studying the biological aspects of the learning instinct. This could mean, first of all, working to verify its existence through a joint research project with brain scientists. If learning is an instinct, then it should be connected to the hormonal system, and its stimuli and appearance might be detectable in the emotional and cognitive sections of the brain. This branch of study is important, since if the learning instinct theory were to be supported by brain studies, it might help shift the focus of schools from the needs of the authorities to the needs of the children. Such a shift is crucial for the adoption of the earth systems approach by schools worldwide.

\section{Objective \#4: Exploring the potential impact of ESE on decision making}

Earth systems education can endow citizens and future citizens with knowledge and abilities with which to draw conclusions for the effective and proper use and conservation of energy, water, and other natural resources. Citizens who understand their environment and its processes are better able to judge and behave in a more 
scientifically aligned way. Moreover, several countries have presented substantial evidence-based data indicating that the Earth systems educational approach can fulfill its potential and, more importantly, how to do it.

The role of ESS education in decision-making research has until now been quite limited, although work is beginning to emerge that asks tantalizing questions about how people make decisions in the face of Earth phenomena (Drost, 2013). Investigation of the mechanisms people use to make decisions about the Earth, both in terms of human impacts on the planet and planetary impacts on humans, is needed to understand how to engender effective decision-making among our citizenry. While the formal education systems focus most closely on content understanding (National Research Council, 2011), the ultimate goal of science education is the development of a scientifically literate public who can make informed decisions about the world (Hazen \& Trefil, 2009; Rutherford \& Ahlgren, 1991).

Effective future research in ESS education should consider all of the variables that are known to be important for decision-making about the Earth system. While some work has considered the role that educational interventions play in changing how students support decisions about complex topics (Grace, 2009), ESS education has still not fully begun to ask questions about real world impacts. For example, we know that people make decisions about the environment that are not always grounded in a rational understanding of science (Bell \& Lederman, 2003). As natural disasters have played a larger role in global discourse, largely made possible by the nearly instantaneous real-time news and video feeds of the internet, ESS education has become increasingly important and clearly inadequate. The challenge of future research is to consider how to move ESS instruction into greater prominence within our educational systems. In light of these growing global needs, the community should focus on work that can build connections between real-world decision-making and what happens in the classroom or other educational settings.

\section{A new avenue of research to help bridge the gap and break the vicious cycle}

While further exploring the four objectives noted above would continue to develop and solidify Earth systems education, strengthening of Earth systems education will, by itself, only deepen the contrast between the research outcomes and the low profile of earth science education in schools. Therefore, the most pressing future research challenge to which research efforts in ESE should be directed is resolving this contradiction and bridging the gap. This section therefore details a series of new directions for future research, all of which revolve around revising the education and the social role of geoscientists.
A deep change in the status of Earth science education in schools requires a deep change in the attitudes of geoscientists towards their social responsibility. This responsibility is part of the professional ethics of a geoscientist, as announced in 2016, during the 35th IGC in Cape Town, South Africa, in the document known as the "Cape Town Statement on Geoethics" (Di Capua, Peppoloni, \& Bobrowsky, 2017). Geoethics deals with the ethical, social and cultural implications of geoscience research and practice, and with the social role and responsibility of geoscientists in conducting their activities. Geoethics includes both internal aspects, related to internal issues within the geoscientist community, and external aspects, related to the geoscientist community's interaction with the public. The inner aspects include issues such as the line between freedom of research and the principles of sustainability, or the line between preservation of the geo-heritage and economic development. The external aspects involve the relationships between geoscientists, media, politicians and citizens. This aspect deals with the responsibility of the geoscientist community to communicate with the public on a regular basis about topics in geoscience, and to inform and educate the public on geoscience issues that are critical to the quality of life - and even the survival - of any local civil community.

Geoscientists can provide information and knowledge about local and global environmental risks and natural hazards. They can inform the public about the air we breathe, the water we drink, the food we eat, the energy we use, the buildings we live and work in, the materials used for our daily lives and the geoheritage that is the basis for local and global tourism. However, as already mentioned above, there are not many geoscientists worldwide who have in interest in interacting with the public, and only few of them have the skills for this level and type of non-academic communication. This situation is rooted in the history of the geoscience discipline, which has influenced the way geoscience students have been educated in universities for centuries.

Significant research effort should therefore be invested among the university geoscience researchers and professors to undertake a deep change in all levels of the university geoscience education programs. This change should include the integration of the following three subjects within the traditional university geoscience disciplinary courses: the earth systems approach, geoethics education, and the development of communication skills. More specifically, research within higher education geoscience teaching should include the following domains:

\section{a) Attitudinal change research:}

Bridging the disturbing gap between the potential of Earth Sciences and its low status in schools requires a 
genuine teaching culture change in schools. However, because modeling is one of the most powerful educational tools, school teachers tend to teach similarly to their university teaching models. The geoscience teaching reform should therefore start in the university level.

Earth science education in higher education worldwide is generally very traditional and conservative. While the content of the courses has been updated to reflect developments in scientific knowledge, the focus and the methods of teaching have hardly changed since the nineteenth century. First year students must still face the same huge drawers filled with hundreds of specimens of rocks, minerals and fossils. The teaching methods focus on memorization and mechanical reproduction of the details of any specimen, most of which are then soon forgotten.

Any personal attitudinal change is a complex and challenging process, and school teachers are no exception in their reluctance to change. Despite its increasing importance, research on instructional design for attitudinal change has been relatively sparse, and lacks cohesion (Mueller, Lim, \& Watson, 2017). The considerable difficulty of teachers to undergo a deep change has been well documented by several studies conducted in this area, as have the factors that might influence a change (e.g. Anghelachea \& BenĠea, 2012; Avidov-Ungar \& MagenNagar, 2014; Zimmerman, 2006). However, very little has been published about the attitudinal change of university lecturers in general, or in particular relation to education in geoscience.

Thus, research in this area should look for the attitudes of academic geoscientists towards aspects such as geoethics, earth systems science and teaching methods. The attitudinal studies should not focus on the description of the attitudes, but look deeper at the origin of these attitudes, to trace the system of variables and forces that perpetuates them. Understanding this attitudinal system should serve as the basis for developing and testing psychological and social models for a personal attitudinal change. The increasing need for education attitude change implies that more research is required to explore instructional principles that can be comprehensively applied to design effective instruction for attitudinal change (Watson, Kim, \& Watson, 2016).

\section{b) Change in expertise:}

As science has expanded into new areas of research, the training of individual scientists has become both narrowly focused on specific research questions and isolated into specific domains. This approach to training limits the interdisciplinary capabilities of new scientists, capabilities that are needed for effective understanding of interdisciplinary fields like ESS. In order to provide effective educational experiences for ESS students, we must first understand what it means to be an Earth systems scientist. Expertise research should also set the stage for reconsideration of the curriculum used to train the new Earth system scientist. These studies should be conducted in the context of attitudinal change towards the exposure of students to the earth systems approach and to the development of system thinking as an integral part of the education of future geoscientists.

\section{c) Geo-ethics:}

Geoethics spans a continuum of concerns, from establishing clear and transparent professional codes of practice to global legal frameworks and governance around Earth system destruction. As noted above, a deep change in the status of Earth science education in schools requires a deep change in the attitudes of geoscientists towards their social responsibility. This responsibility is part of the professional ethics of the geoscientist (Di Capua et al., 2017). Geoethics also deals with the ethical, social and cultural implications of geoscience research and practice as these relate to the geoscientist community's interaction with the public. The growing evidence that citizens value the importance of science and need to be more informed regarding global problems (such as climate change, mineral exploitation or how to protect bio- and geodiversity) proves that the emergence of Geoethics is an imperative whenever human activities interact with the Earth System. Nevertheless, because it is a new field of Geoscience, disseminating Geoethics knowledge is a pressing task for future geologists and geology teachers, as well as for students and citizens (Vasconcelos, Torres, Vasconcelos, \& Moutinho, 2016).

The recognition of this breadth of concerns has led to the launch of the GOAL (Geoethics Outcomes and Awareness Learning) Erasmus Plus project. This international partnership is mining the expertise of members from 6 countries (Portugal, Italy, Israel, Austria, Lithuania and Spain) in overlapping interdisciplinary areas in order to develop a Geoethics syllabus. The project also aims to offer suggestions of educational resources that can be used in higher education to enhance the quality and relevance of students' knowledge and skills. The pillars of Geoethics are rooted in a set of values that are divided into three partially overlapping groups: ethical values, cultural values and social values (Peppoloni \& Di Capua, 2016). The integration of Geoethics values as an integral part of the education array of a future geoscientist could lead to the production of more geoethically literate geoscientists, who show more awareness of their social role.

d) Interaction with the public: 
The interaction of the geoscience community with the public can be done in two levels: the young generation level and the adult level. While the school system is the main channel for interaction with children, interaction with adults (and children) can be carried out through a variety of channels, such as TV, newspapers, internet (Facebook, Twitter, Instagram), geoparks and natural parks. Intensive research should therefore be conducted to better understand what communication and educational strategies should be adopted to convey the value of the geoscience to society, and to suggest effective ways of encouraging geoscience professors to move from 'frontal' traditional teaching towards a more progressive teaching method. The latter effort could include, for example, introducing inquiry based learning indoors and outdoors, or integrating geological field trips as an integral part of the teaching sequence rather than placing them, as is customary, at the end of the teaching sequence. It could also include project-based learning, cooperative learning and the integration of geoethics values. Moreover, since a very important geoethics value is communication skills with laypeople who are unfamiliar with the scientific jargon and lacking in scientific background, a central part of the research at the university level should be a design-based research type. Such studies would focus on the development of learning activities and teaching strategies for the development of geoethics values through geoscience university programs. Effective teaching tools directed at the development of awareness for Geoethics are also needed, to help young people become conscious and active citizens (Vasconcelos et al., 2016). The inclusion of the field of geoethics in formal education must be accompanied by a greater conceptual development, translated, for example, by a greater number of publications that address it theoretically, while also highlighting its applicability (Almeida \& Vasconcelos, 2015).

\section{e) Training of ESS Education Researchers:}

All the above studies require the preparation of very skillful Earth science education researchers, which can be achieved only by or with the collaboration of geoscience university departments. The most effective ES education researchers are those scholars who are able to transcend disciplinary boundaries and move seamlessly between different fields of inquiry. For example, a scholar investigating the impact of formal ES education on the decision-making processes of the general public would need to be well-versed in concepts and research norms from the Earth systems science, formal science education, public understanding of science, and decision-making fields. These fields are themselves interdisciplinary, potentially calling upon scholarship in Earth science, education, psychology, learning science, social science, communication, and beyond. Training new researchers with the fluidity to move across disciplinary boundaries is a challenge that faces many fields, and certainly something that requires investigation for ES education. At the very least, we need evidence-based training opportunities for scholars to expand our understanding of how people perceive, learn about, and understand Earth systems, and we need to consider how we can more effectively value interdisciplinary scholarship that belongs in many traditional departments.

\section{Conclusions}

The narrowing of the disturbing gap between the educational potential of Earth Science and its low profile in schools requires a new, holistic research agenda. This agenda should encompass both the deepening of the existing research of the Earth systems approach, and an investment in new avenues of research designed to enlist the massive support from the geoscience community that will be required to fully address the problem and raise the status of Earth science in schools. Above all, we can conclude that a well-trained next generation of scholars is absolutely necessary if we are to meet the pressing need for building learning experiences that enhance the reform of traditional ES teaching in both universities and schools. That new well trained generation is the great future challenge of Earth science education research.

\section{Abbreviations}

ES: Earth Science; ESE: Earth Science Education; ESS: Earth System Science; GOAL: Geoethics Outcomes and Awareness Learning; IGEO: International Geoscience Education Organization; SW: Social wellbeing

\section{Acknowledgements}

Not relevant.

Authors' contributions

The author declares that he is the only author and therefore the only contributor of this article. The author read and approved the final manuscript.

\section{Funding}

The author declares that there is no funding for this study.

\section{Availability of data and materials}

This manuscript was invited by editor of the journal who asked for my view of the future challenges of Earth science education. The subjective argumentation presented in this manuscript is based on the database of the studies that were cited and referenced in this article. Thus, data sharing is not applicable to this article as no direct datasets were generated during the current study.

The data that support the findings of this study might be available from authors of the cited studies which appear in the references of this article. 
Received: 24 May 2019 Accepted: 12 August 2019

Published online: 28 November 2019

\section{References}

Abraham, M. R. (1976). The effect of grouping on verbal interaction during science inquiries. Journal of Research in Science Teaching, 13, 127-135.

Almeida, A., \& Vasconcelos, C. (2015). Geoethics: master's students knowledge and perception of its importance. Research in Science Education, 45(6), 889906. https://doi.org/10.1007/s11165-014-9449-3.

Anghelachea, A., \& BenĠea, C. (2012). Educational changes and teachers' attitude towards change. Procedia - Social and Behavioral Sciences, 33, 593-597.

Avidov-Ungar, O., \& Magen-Nagar, N. (2014). Teachers in a changing world: Attitudes toward organizational change. Journal of Computers in Education. https://doi.org/10.1007/s40692-014-0014-X.

Bell, R. L., \& Lederman, N. G. (2003). Understandings of the nature of science and decision making on science and technology based issues. Science Education, 87(3), 352-377.

Di Capua, G., Peppoloni, S., \& Bobrowsky, P. (2017). The Cape Town statement on Geoethics, doi: 10.4401/ag-7553. In S. Peppoloni, G. Di Capua, P. T. Bobrowsky, \& V. Cronin (Eds.), Geoethics at the heart of all geoscience, Annals of Geophysics, 60, Fast Track 7. https://doi.org/10.1007/s11528-017-0191-3.

Drost, R. (2013). Memory and decision making: Determining action when the sirens sound. Weather, Climate, and Society, 5(1), 43-54.

Eyov, L. (2017). The earth science cross-country class as an intersection point between formal and informal education. Rehovot: Unpublished master's thesis, the Weizmann Institute of Science.

Foster, G. W., \& Penick, J. E. (1985). Creativity in a cooperative group setting. Journal of Research in Science Teaching, 22, 89-98.

Grace, M. (2009). Developing high quality decision-making discussions about biological conservation in a normal classroom setting. International Journal of Science Education, 31(4), 551-570.

Greco, R., \& Almberg, L. (Eds.) (2018). Earth science education: Global perspectives, (p. 355). Pouso Alegre: IFSULDEMINAS il. ISBN: 987-85-67952-14-7.

Hazen, R. M., \& Trefil, J. (2009). Science matters: Achieving scientific literacy (Reprint.). Anchor.

Hoffman, M., \& Barstow, D. (2007). Revolutionizing Earth system science education for the 21st century. In Report and recommendations from a 50state. Analysis of earth science education standards. Cambridge: TERC.

Humphreys, B., Johnson, R. T., \& Johnson, D. W. (1982). Effects of cooperative, competitive, and individualistic learning on students' achievement in science class. Journal of Research in Science Teaching, 19, 351-356.

Imig, D., \& Imig, S. (2006). The teacher effectiveness movement: How 80 years of essentialist control have shaped the teacher education profession. Journal of Teacher Education, 57(2), 167-180.

Johnson, R. T. (1976). The relationship between cooperation and inquiry in science classrooms. Journal of Research in Science Teaching, 13, 55-63.

Keyes, C. L. M. (1998). Social well-being. Social Psychology Quarterly, 61, 121-140.

Keyes, C. L. M. (2002). The mental health continuum: From languishing to flourishing in life. Journal of Health and Social Behavior, 43, 207-222.

King, C. (2013). Geoscience education across the globe - Results of the IUGSCOGE/IGEO survey. Episodes, 31, 19-30.

King, C., Orion, N., \& Thompson, B. D. (1995). Earth sciences education on the world stage. School Science Review, 77(279), 121-124.

Levy, I., Kaplan, A., \& Assor, A. (2004). Academic achievement goal structures and young adolescents' biased preferences for peers as cooperation partners: A longitudinal study. Social Psychology of Education, 7, 127-159.

Martin, R. E. (2018). Earth's evolving systems: The history of planet earth. Massachusetts: Jones \& Bartlett Learning.

Mueller, C., Lim, J., \& Watson, S. L. (2017). First principles of attitudinal change: A review of principles, methods and strategies. Tech Trends, 61, 560-569.

National Research Council (2011). A framework for K-12 science education: Practices, crosscutting concepts, and core ideas. Washington, D.C.: The National Academies Press

Okebukola, P. A., \& Ogunniyi, M. B. (1984). Cooperative, competitive, and individualistic science laboratory interaction patterns-Effects on students' achievement and acquisition of practical skills. Journal of Research in Science Teaching, 21, 875-884

Orion, N. (2007). A holistic approach for science education for all. Eurasia Journal for Mathematics, Science and Technology Education, 3, 99-106.
Orion, N. (2016). Earth systems education and the development of environmental insight. In C. Vasconcelos (Ed.), Geoscience education: Indoor and outdoor (pp. 59-72). Cham: Springer.

Orion, N. (2017). The relevance of earth science for informed citizenship: Its potential and fulfillment. In L. liete, L. Dourado, and S. Morado (Eds). Contextualizing teaching to improving learning (pp. 41-56). New York: Nova Science Publishers.

Orion, N., Adams, P., King, C., \& Krockover, J. (1999). The development and status of earth science education: A comparison of three case studies: Israel, England and Wales, and United States of America Part 1. ICASE, 10(2), 13-23.

Orion, N., \& Ault, C. (2007). Learning earth sciences. In S. Abell, \& N. Lederman (Eds.), Handbook of research on science teaching and learning, (pp. 653-688). USA: Lawrence Erlbaum Associates.

Orion, N., \& Fortner, W. R. (2003). Mediterranean models for integrating environmental education and earth sciences through earth systems education. Mediterranean Journal of Educational Studies, 8(1), 97-111.

Orion, N., \& Libarkin, J. (2014). Earth systems education. In S. Abell, \& N. Lederman (Eds.), Handbook of research on science teaching and learning. USA: Lawrence Erlbaum Associates.

Peppoloni, S., \& Di Capua, G. (2016). Geoethics: Ethical, social, and cultural values in geosciences research, practice, and education. In G. R. Wessel, \& J. K. Greenberg (Eds.), Geoscience for the public good and global development: Toward a sustainable future, (pp. 17-23). Boulder: Geological Society of America

Robitschek, C., \& Keyes, C. L. M. (2009). Keyes's model of mental health with personal growth initiative as a parsimonious predictor. Journal of Counseling Psychology, 56(2), 321-329. https://doi.org/10.1037/a0013954.

Rutherford, F. J., \& Ahlgren, A. (1991). Science for all Americans, (2nd ed., ). USA: Oxford University Press.

Sterling, S. (2010). Living in the earth: Towards an education for our time. Journal of Education for Sustainable Development, 4(2), 213-218.

Vasconcelos, C., Torres, J., Vasconcelos, L., \& Moutinho, S. (2016). Sustainable development and its connection to teaching Geoethics. International Union of Geological Sciences, 39(3), 509-517. https://doi.org/10.18814/epiiugs/2016/ v39i3/99771.

Vygotsky, L. S. (1962). Thought and language. Cambridge: MIT Press.

Watson, W. R., Kim, W., \& Watson, S. L. (2016). Learning outcomes of a MOOC designed for attitudinal change: A case study of an animal behavior and welfare MOOC. Computers \& Education, 96, 83-93.

Zimmerman, J. (2006). Why some teachers resist change and what principals can do about it. NASSP Bulletin, 90(3), 238-249.

\section{Publisher's Note}

Springer Nature remains neutral with regard to jurisdictional claims in published maps and institutional affiliations.

\section{Submit your manuscript to a SpringerOpen ${ }^{\odot}$ journal and benefit from:}

- Convenient online submission

- Rigorous peer review

- Open access: articles freely available online

- High visibility within the field

- Retaining the copyright to your article

Submit your next manuscript at $>$ springeropen.com 